\title{
LITERATURA E ENSINO: “QUEM SABE LER ENXERGA MELHOR..."
}

\author{
Armando Gens ${ }^{2}$
}

\begin{abstract}
Resumo. Este artigo pretende problematizar as receitas de sucesso da literatura e seu sistema canônico a partir de um franco debate dos modelos de ensino que investem em falar sobre o texto literário de uma forma secundária, segregandoo a um espaço de apagamentos e emudecimentos decorrentes de leituras de segunda mão. Como saída para esses impasses, propõem-se centralizações no texto literário, reivindicando o estabelecimento de um espaço poético construído pela subjetividade e por leituras autorais com base em experiências artísticas que invistam em redes interdisciplinares. Como base teórica, apresentam-se as contribuições sobre esse tema de Showalter, Todorov, Montes e Caron.
\end{abstract}

Palavras-chave: ensino, texto literário, espaço poético.

\section{LITERATURE AND TEACHING: "WHO KNOWS HOW TO READ SEES BETTER"}

\begin{abstract}
This article intends to raise questions about the successful recipes of the literature and its canonical system from a frank debate of the models of education that invest in talking about the literary text in a secondary way, segregating it to a space of erasures and muting from second hand readings. As an outlet for these impasses, centralizations are proposed in the literary text, claiming the establishment of a poetic space constructed by subjectivity and by authoritative readings based on artistic experiences that invest in interdisciplinary networks. As a theoretical basis, contributions by Showalter, Todorov, Montes and Caron about this theme are presented.
\end{abstract}

Keywords. teaching, literary text, poetic space.

\footnotetext{
${ }^{1}$ Este texto foi apresentado no VII Seminário Nacional Literatura e Cultural, na UFS, em agosto de 2016 Essa citação nos remete a um quadro atual de urgência em valorizarmos a leitura do texto literário (VAZ, 2016. p. 144).

2 Prof. Dr. da Faculdade de Formaação de Professores da UERJ.
}

Pontos de Interrogaçăo, v. 6, n. 2, jul.-dez., p. 161-178, 2016. 


\section{Introdução}

O final da segunda década do século XXI se aproxima. Se ainda é cedo para uma avaliação mais consistente, não é tarde para constatar que o contexto educacional brasileiro passa por um período de assentamentos e estabilizações, o que permite, portanto, admitir a presença de uma tendência nos estudos e nas investigações centradas no trabalho didático que pende para as experiências didático-pedagógicas positivas com grande margem de êxito. Há mesmo uma vontade construtiva de buscar soluções, saídas e recursos para minimizar a crise da leitura literária e do ensino de literatura que se instalou na Educação Brasileira. Ações louváveis que, sem dúvida, começam a afastar os "fantasmas" trazidos pela crise e a espanar o derrotismo e a descrença por ela desencadeados. No entanto, ainda que ações, intenções e práticas convirjam para a restauração de um contexto deteriorado, não se pode negligenciar a importância das avaliações que se preocupam em conferir validade e legitimidade do que vem sendo proposto e realizado no ensino da leitura e da literatura nos diferentes níveis de ensino, e tampouco desconsiderar a interação entre a Educação Básica e os diferentes graus de formação acadêmica -- Licenciatura, Normal Superior, Magistério, Pedagogia.

Contudo, levando-se em consideração o espaço e os receptores deste texto, impõe-se a ele uma natural centralidade em um curso de Pós-graduação stricto sensu em Letras destinado a capacitar professores para o exercício da docência no Ensino Fundamental. Por conseguinte, a focalização abrange o ensino superior e seu engajamento com a formação e a capacitação de professores do Ensino Fundamental, sabendo-se, de antemão, que, no catálogo das disciplinas do PROFLETRAS, apenas uma contempla a literatura como disciplina obrigatória: "Leitura do texto literário". Em resumo, a literatura aparece rarefeita. Logo, onde encontrar ali a literatura? Em Letramento, Linguagem, Língua Portuguesa, Leitura? E se existe alusão à literatura, ela se apresenta de forma adjetiva e indireta. Comprove-se: "identidades e construções antropo-culturais e literárias"; “estudos voltados para a linguagem, o que lhe possibilitará uma posição madura intelectualmente, permitindo-lhe posicionar-se frente à realidade linguística 
do aluno nos mais diferentes níveis, associados à linguagem e à sua leitura de mundo". (http://capes.gov.br/educacao-a-distancia/profletras).

Isso posto, cabe indagar o que se pode dizer a respeito do ensino de literatura em tempos de moldagens, receitas de sucesso e espetacularização da disciplina (SARLO, 2005)? O que se pode dizer de uma disciplina que dizem ter desaparecido? O que se pode dizer a respeito do ensino de literatura que ainda se organiza segundo um sistema arbóreo (DELEUZE; GUATTARY, 1995)? $O$ que se pode dizer a respeito do ensino de uma disciplina que presta culto e celebra o cânone oficial (ANDREATO, 2012)? Despido da pretensão de responder a tais perguntas, este texto pretende problematizá-las, uma vez que o objetivo nuclear reside em um franco debate com modelos de ensino (SHOWALTER, 2007) que investem em falar sobre o texto literário (TODOROV, 2009), em confiná-lo a um espaço de apagamentos e emudecimentos decorrentes de leituras de segunda mão. Assim, propondo dinamizações com o texto literário, reivindica-se o estabelecimento de um espaço poético (MONTES, 1999) construído pela subjetividade (CARON, 2012) e por leituras autorais com base em experiências artísticas que invistam em redes interdisciplinares.

Antes de problematizar as questões já registradas, recorre-se a um fragmento de um texto de Sérgio Vaz, intitulado "Literatura, pão e poesia":

A periferia nunca esteve tão violenta: pelas manhãs, é comum ver, nos ônibus, homens e mulheres segurando armas de até quatrocentas páginas. Jovens traficando contos, adultos, romances. Os mais desesperados, cheirando crônicas sem parar. Outro dia um cara enrolou um soneto bem na frente de minha filha. Dei-lhe um acróstico bem forte na cara. Ficou com a rima quebrada por uma semana.

A criançada está muito louca de história infantil. Umas já estão tão viciadas, e, apesar de tudo e de todos, querem ir para as universidades. Viu, quem mandou esconder ela da gente, agora a gente quer tudo de uma vez! (2011, p. 47)

O fragmento, como se fosse uma pedrada, atinge o cerne dos preconceitos e propõe uma reconfiguração das imagens correntes atribuídas aos que vivem na periferia. Através de deslocamentos de sentido, Sérgio Vaz 
redefine e ressimboliza o contexto literocultural da periferia através da instauração de um espaço poético que promove mudanças na condição determinista a que os sem acesso aos bens culturais estavam submetidos. Como se pode observar, a violência transforma-se em uma força construtiva que oferece a crianças, homens e mulheres a possibilidade de transformar histórica e culturalmente o lugar com o qual mantêm pertencimento. A literatura e a leitura literária bem podem representar um tipo de violência -a que está presente em todo ato de criação -- que oferece condições para combater os estados de vulnerabilidade. Trata-se de um tipo de energia erotizante, que alavanca o desejo de romper as cadeias deterministas, como bem ilustram as palavras do poeta Sérgio Vaz.

Este sentido transformador atribuído à literatura não é apenas um jogo retórico nem fruto de ânimos exaltados. Na verdade, ele encontra respaldo em inúmeros estudos sobre a função terapêutica da literatura, como atestam os trabalhos de Michèle Petit. Neles, a antropóloga ressalta o importante papel da leitura literária na construção ou na reconstrução de subjetividades de crianças, jovens e adultos em condições adversas ou ainda como antídoto contra a frágil e alienante capitalização do self que o mercado deseja impor e impõe. Por isso, tais dimensões devem ser consideradas, pois, quando se pensa em ensino de literatura, há que se levar em conta um método de ensino que possa oferecer condições aos estudantes de terem de volta a dignidade e a humanidade que lhes foram negadas ou sequestradas. Em sendo assim, conforme recomenda Michèle Petit,

[...] não é um luxo poder pensar a própria vida com a ajuda de obras de ficção ou de testemunhos que tocam no mais profundo da experiência humana. De obras que nos ensinam muito sobre nós mesmos, e muito sobre outras vidas, outros países e outras épocas. Parece-me inclusive que seja um direito elementar, uma questão de dignidade. (2008, p. 78)

As palavras de Michèle Petit vêm ao encontro das atuais demandas da educação brasileira, porque a inclusão, em todas as suas formas, passou a ser uma linha de força de um projeto educacional brasileiro que propõe investir em ações mais democráticas. Mediante tais ações, o aumento das 
possibilidades de acesso à educação e a diversidade dos perfis de estudantes fazem com que as instituições de ensino tenham de repensar métodos e didática, para garantirem a proclamada qualidade de ensino. E, diante desse quadro institucional, os professores também são motivados a repensar o que é ser um educador comprometido com o ensino da leitura e da literatura.

Se a intenção desse texto recai sobre um ensino destinado a segmentos sociais que, por diferentes causas, são excluídos do espaço da leitura e da literatura, é muito importante registrar que ações têm sido realizadas para a reversão de um contexto de tamanha desigualdade. Pelo que se observa, instituições de ensino e seus respectivos professores demonstram um compromisso maior com o afeto, "com a dor dos outros", com contextos e culturas antes desconsideradas. Sem dúvida, a despeito de todas as dificuldades e entraves concernentes às políticas públicas, houve significativas mudanças no ensino da literatura, como demostram a variedade didática e metodológica para tal finalidade. Porém, a referida variedade mantém pontos de contato, quando se trata de promover as seguintes orientações: a autonomia do leitor, as questões suscitadas pelo valor atribuído a textos literários, a relevância da recepção, o horizonte de expectativas, a ampliação e renovação do cânone, entre outros.

Ainda sobre o efeito terapêutico da literatura e da leitura literária nos estudantes, cumpre assinalar que o espaço poético é uma forma de habitar, pois franqueia a possibilidade de diálogo do interior com o exterior, alimenta o imaginário com imagens, promove a meditação, organiza o caos e as mentes confusas. Para compreender tal forma de habitar, Michèle Petit diz que "as obras literárias esbanjam paisagens sem conta, incitando cada um a compor sua própria geografia. Contos, lendas, livros ilustrados, romances oferecem uma topografia, balizam o espaço, abrem-no para o exterior." (PETIT, 2009, p. 93-94). Vê-se que essa forma de habitar se realiza através do transporte que a imaginação criadora favorece, quando entra em contato não só com o texto literário, mas também com ele. No entanto, para que este transporte se realize, é importante que se conceda especial atenção aos afetos. Nada acontecerá se, nas instituições de ensino, houver a reprodução 
da violência, da incompreensão, da intolerância e da humilhação vividas diariamente por muitos estudantes.

Cabe esclarecer que essa forma de habitar não leva à alienação. Não se trata de uma válvula de escape. Define-se como um modo de enfrentar realidades adversas em um plano simbólico. O transporte possibilita encontrar no texto literário aquilo que foi negado, sequestrado, subtraído pela perda, pela vulnerabilidade socioeconômica e pelas situações traumáticas, como atesta o trecho de "Literatura, pão e poesia", de Sérgio Vaz, citado anteriormente. Como se pode verificar, o poeta narra com muita propriedade o desarmamento simbólico das marcas do contexto periférico agenciado pela leitura e pela literatura: armas pesadas e drogas. No discurso do poeta, em lugar da deterioração costumeiramente atribuída à periferia, encontra-se um sentimento de revolta organizada que alavanca a ocupação do espaço poético enquanto forma de habitar. E, por mais contraditório que pareça, tudo indica que, em certos casos, é da revolta que emerge, despido de qualquer pieguice, o amor à leitura literária e à literatura. O sentimento de revolta faz todo o sentido, quando se sabe que "Página e país têm a mesma etimologia" (PETIT, 2009, p. 93), pois derivam da palavra latina pagus, que significa campo ou unidade territorial, e que revolta, por sua vez, origina-se de revolvere, dar voltas, revirar a terra, girar. Revirar a página, revirar a "terra", revirar a história devem ser as intenções primeiras dos projetos que visam à formação do leitor literário. Assim, enquanto a "revolta" pressupõe um sentimento de indignação contra uma ordem para que se instaurem, no caso da citação de Sérgio Vaz, novos pactos sociais e culturais, o sentido de giro nele presente endereça os habitantes da periferia para esta forma de habitar da qual Michèle Petit nos fala. Forma de habitar somente possível se houver amor.

Provavelmente, falar do amor seja um ponto muito delicado e dolorido na história do ensino da leitura e da literatura. Sabe-se o quanto instituições e escolas são frágeis em dar respostas positivas a este quesito, pois uma série de fatores estão sempre a barrar a entrada da amorosidade em suas dependências. De modo geral, a leitura e o texto literário, em acepção escolar, na maioria das vezes, estão vinculados a critérios de utilidade, de usos e de padrões objetivos de avaliação. O texto, enquanto tecido semântico, terá 
suas tramas torcidas para dar conta de interesses didáticos, a saber: veicular um conselho, uma história exemplar, uma advertência, etc... Ou por outra, servir de mostruário, por exemplo, para técnicas de escrita, regras e normas de metrificação, figuras retóricas, estilos de época, estruturadores da narrativa, gêneros textuais, gêneros discursivos, entre tantas outras possibilidades.

Diante do conciso rol das coisas úteis previstas ao ensino da leitura e da literatura, percebe-se que não há um investimento nas camadas da subjetividade. Prevalece um conjunto de práticas que impendem os estudantes de habitarem o texto literário. Por isso, com muita propriedade, Michèle Petit, em Os jovens e a leitura: uma nova perspectiva (2008), observou que, na França, "Ao privilegiar as técnicas de decifração do texto, as abordagens inspiradas na semiologia e na linguística aumentavam a distância em relação aos próprios textos" ( p.157). Embora a observação da pesquisadora esteja ancorada no sistema de francês, não se pode negar que ela tem sua validade no contexto educacional brasileiro.

Também não se pode negar que muitos estudantes brasileiros aprendem a amar a leitura e a literatura na escola, e que eles constroem significativos repertórios de leitura durante o período de escolarização. Porém, mais uma vez há que se concordar com Michèle Petit, quando ela, com base em depoimentos de leitores, diz que "Hoje, como em outras épocas, ainda que "a escola" tenha todos os defeitos, sempre existe algum professor singular, capaz de iniciar os alunos em uma relação com os livros que não seja a do dever cultural, a da obrigação austera" (PETIT, 2009, p. 158). Fica patente que a singularidade a que ela se refere só pode ser parte integrante de professor que "tenha experimentado esse amor" (PETIT, 2008, p. 161).

Sobre o "regime do amor" (PETIT, 2009, p. 102), cabe esclarecer que se trata de um regime que vai potencializar os leitores. Ele é responsável pela vitalidade que conduz os estudantes a habitarem no espaço poético. Fica muito claro que se está diante de uma manifestação erótica que promove gozo em si mesmo e que oferece a possibilidade de resgate da totalidade perdida (BRANCO, 1987, p.14). Para esclarecer a dimensão erótica experimentada na leitura literária, torna-se crucial evocar o mito de Eros. Sabe-se que existem 
várias versões, mas a que melhor se coaduna com o sentido aqui atribuído refere-se àquela em que Eros é filho da penúria e da esperteza. Nesta versão, o amor caracteriza-se como uma falta que se preenche através de manobras.

Elaborando uma ponte entre a leitura literária e o mito grego, entende-se que o "regime da leitura" se instala quando os estudantes direcionam o impulso vital para o espaço poético e, neste espaço -- forma de habitar -- resgatam a plenitude perdida através de artimanhas, para compreender o que leem em conjunção com o mundo e com suas histórias de vida. Daí, decorre a importância do "regime do amor", uma vez que existem práticas escolares que desmobilizam os estudantes e retiram deles o direito de criar pertencimento com o espaço poético e a possibilidade de ultrapassar barreiras que vedam a compreensão do mundo, dos outros e de si mesmo.

Parece bastante claro que o "regime do amor" restitui a capacidade de olhar o mundo, as coisas e os semelhantes de forma mais humana. Ele funciona como um medicamento para o olhar doente, o olhar viciado, o olhar que nada vê além de imagens de um mundo particular e autocentrado em experiências pessoais. O "regime do amor" amplia o campo de visão e leva os estudantes a ficarem mais "curiosos e questionadores" (PETIT, 2009, p.102), "atentos aos detalhes, e a se surpreenderem com eles" (Idem). É com toda razão que Sérgio Vaz, em "Oficina de poesia 1", proclama: "Quem lê enxerga melhor..." (VAZ, 2016, p. 144). Cumpre esclarecer que o sentido de olhar e de enxergar não se restringe apenas ao órgão mencionado, mas também se estende e desdobra nas relações entre olho-pensamento, olho-tato, olhoaudição.

Há que se reconhecer que o ensino de literatura e da leitura literária nem sempre segue o "regime do amor". Por vezes, as instituições se veem compelidas a apelar para a espetacularização da literatura. Em nome da contextualização e da correlação com a realidade do aluno, malabarismos são feitos para que estudantes se aproximem dos textos literários. Se por um lado as habilidades de leitura dos estudantes são questionáveis, por outro a inabilidade de certos professores em lidar com a resistência dos estudantes, no que diz respeito à leitura, também acaba criando uma série de entraves ou facilidades que reforçam a rejeição a ler. Neste sentido, Beatriz Sarlo, em "A 
escola em crise", destaca que a "escola carece de ideais para transmitir e isto afeta desde o ensino da língua até a discussão de temas morais" (SARLO, 2005, p. 99) e sublinha que, para certos "segmentos sociais", a "escola é o único meio de apropriação de uma cultura que não seja mass-midiática. " (p.101), já que "Toda cultura que conhecemos [...]é uma construção edificada em um sentido que vai contra a espontaneidade." ( p. 104)

O que Beatriz Sarlo quer ressaltar é que a escola, ao supervalorizar os interesses dos estudantes, "converte a transmissão cultural em um simulacro pálido e demagógico da cultura adolescente. " ( p.104). Para a pesquisadora, a escola é "juvenilista" ( $\mathrm{sic}$ ), pois tenta agradar os jovens como se fossem clientes. Que o ensino deve ser sedutor e interessante é o lema das escolas que seguem este padrão. Destaca a cronista do Clarín que deste procedimento decorrem uma série de crenças que reduz as possibilidades dos estudantes de entrarem em contato com outras culturas que sejam diferentes das suas e exigem do professor um perfil performático. De modo geral, o apelo à cultura de massa tem grande rendimento neste tipo de abordagem e expõe os estudantes a materiais que já conhecem: filmes, imagens e textos que fazem parte da realidade do alunado. O livro grosso, o texto longo e os autores do passado são também facilmente substituídos, com muita frequência, por textos curtos, enredos digestivos e narrativas aceleradas. Um exemplo bem expressivo encontra-se na prevalência dos gêneros conto, crônica, fábula em projetos de leitura. O poema ${ }^{3}$, por sua vez, salvo algumas exceções, ainda é um gênero de pouco rendimento e vinculado a comemorações e datas especiais.

Em resumo, a espetacularização da literatura acaba ainda por minimizar a importância do texto literário em detrimento de outros materiais e eclipsá-lo com uma série de recursos didáticos centrados em imagens visuais e produtos do mass-mídia. No melhor estilo do professor John Keating, personagem do filme Sociedade dos poetas mortos (1989), o ensino convertese em performance que parece revolucionar, mas que acaba por favorecer a construção de identidades reguladas pelas leis do mercado. A literatura,

\footnotetext{
${ }^{3}$ Cf. GENS, Armando. Poesia e ensino: O que será para uma borboleta rebocar um batelão! Acesso: www.e-publicacoes.uerj.br/index.php/pensaresemrevista/article/view/14109
} 
situada nessa frequência exibida pelo filme dirigido por Peter Weir, ganha uma função redentora e mostra-se cheia de glamour. Visão ingênua e encantatória que reduz as possibilidades de confronto e de resistência culturais, de forma que a literatura seja tão somente um instrumento de combate ao tradicionalismo e às formas autoritárias do poder, uma forma do tempo e não do espaço do ser da linguagem em seu primeiro lance (FOUCAULT, 2016, p.105). Privilegia-se, igualmente, uma linguagem que fala sobre a literatura, como advertem Foucault ${ }^{4} \mathrm{e}_{\text {Todorov }}{ }^{5}$.

São muitos os recursos de sedução aplicados em sala de aula para aproximarem estudantes da literatura e da leitura literária. Dentre eles, ainda se destaca a leitura espontânea e sem a interferência do professor. É claro que as posições de Daniel Pennac estão na base de tais procedimentos, já que ele levantou a bandeira sobre os direitos e a autonomia de leitores, estimulando práticas que um dia foram consideradas insurretas, a saber: não ler, pular páginas, não finalizar a leitura, entre outros tantos direitos. Porém, considerando-se o contexto cultural das escolas públicas brasileiras, não parece que tais práticas contribuam para a formação de leitores, pois, muitas vezes, o estudante brasileiro vai ter o primeiro contato com livros quando ingressa na escola. O que pode ser bom para as escolas francesas pode não o ser para as brasileiras, pois a realidade escolar do Brasil reivindica outras práticas para a formação de leitores de textos literários, uma vez que o contexto cultural ainda é muito pouco democratizado.

Mais em consonância com a realidade do sistema educacional brasileiro, estão as propostas que Bettina Caron faz, em Posmodernidad y lectura: la lectura literaria en la construcción de la subjetividad. Primeiramente, porque a ideia central da autora argentina é desenvolver a leitura literária como interferência na cultura midiática. Em segundo lugar, porque a autora apresenta um projeto de leitura bem planejado que privilegia

\footnotetext{
${ }^{4}$ Cf. "Forma-se, hoje em dia, uma relação muito diferente entre a linguagem que se pode chamar primeira, e a que chamamos mais simplesmente literatura, e essa segunda, que fala da literatura, e que normalmente chamamos de crítica." (2016, p. 105)

${ }^{5} \mathrm{Cf}$. "Na escola, não aprendemos acerca do que falam as obras, mas sim do que falam os críticos." (2009, p.27)
} 
conversas, vivências, recordações com o objetivo de fazer com que os estudantes se busquem como leitores. Vale, então, registrar as palavras de Bettina Caron, quando comenta a posição de Tourraine sobre a busca da identidade:

Es aqui donde cabe associar el concepto de construcción de la subjetidad -- de la que venimos hablando em relación com la lectura como trabajo psíquico, como constuctora, diríamos, del self, principalmente em la infancia y la adolescencia -- com el de sujeto, en la concepción de Tourraine. El sujeto que no solo se hace dueño del mundio emocional y de sus experiencias -- el self --, sino también de sus deerechos sociales al trabajo y la vida cívica, y muy especialmente, de sus derechos culturales: su lengua, sus creencias, su sexualidade, su propia vida em relación con los otros. (CARON, 2012, p. 77)

Estes sim são os direitos que cabem ao sistema educacional brasileiro. A leitura e a literatura podem oferecer aos estudantes a possibilidade de se construírem como sujeitos que interrogam e buscam ultrapassar regras, fronteiras, limites e pressões diversas que colocam barreiras de contenção e que bloqueiam o desejo de ser o que se quer ser. O sujeito será aquele que oferece resistência a tudo que possa ameaçar a sua identidade: o consumo, as leis do mercado, a ditadura tecnológica, a segregação, a exclusão, os artefatos eletrônicos, a exposição promovida pelas redes sociais, e, sobretudo, a perda de identidade pessoal que vai sendo substituída pela capacidade de interagir com diferentes pessoas em escala mundial. Neste sentido, segundo Bettina Caron," "la lectura literária puede funcionar como un antídoto humanizante para la construcción de la subjetidad, y así actuar como interferencia necessária en la cultura mediática" ( p. 15), porque franqueia "experiências genuínas" em um mundo pasteurizado, programado pelo mercado e assistido por máquinas.

Outro ponto que merece ser discutido tanto no ensino da literatura quanto no da leitura diz respeito ao modelo arbóreo que ainda persiste na organização dos saberes escolares. Acerca deste modelo pode-se dizer que ele se estrutura segundo uma forma vegetal: a da árvore -- raízes bem fundas, tronco, ramificações e frondosidade. Trata-se de uma lógica 
binária que precisa de uma unidade central. Contudo, de acordo com Gilles Deleuze e Félix Guattari, “O pensamento não é arborescente e o cérebro não é uma matéria enraizada nem ramificada." (DELEUZE; GUATTARI, 1995, p. 34). Por isso, os autores propõem uma complexa teoria com base no rizoma que,

diferentemente das árvores e de suas raízes, [...] conecta um ponto qualquer com outro ponto qualquer e cada um de seus traços não remete necessariamente a traços da mesma natureza; ele põe em jogo regimes de signos muito diferentes, inclusive estados de não signos. O rizoma não se deixa reconduzir nem ao Uno nem ao múltiplo. Ele não é o Uno que devém dois, nem mesmo que deviria diretamente três, quatro ou cinco tec. Ele não é múltiplo que deriva do Uno, nem ao qual o Uno se acrescentaria $(\mathrm{N}+1)$, Ele não é feito de unidades, mas de dimensões, ou antes de direções movediças. Ele não tem começo nem fim, mas sempre um meio pelo qual ele cresce e transborda. (DELEUZE; GUATTARI, 1995, p. 43)

Pensando na possibilidade de uma reconfiguração do ensino de literatura e da leitura que ainda acontece segundo uma estrutura arborescente, é essencial que se vá buscar uma provocação na teoria do rizoma. Embora se saiba que ainda há um longo caminho a ser percorrido para reverter o atual quadro binário, unívoco e hierarquizado que rege a organização dos saberes e as disciplinas escolares, torna-se produtivo levantar suspeitas acerca dos modelos radiculares e arborescentes. Seria interessante que os convencionais planejamentos fossem substituídos por mapas em que, ao contrário de uma ordenação linear e segmentada, capturassem um "movimento transversal ", sem início e sem fim, em multiplicidades cambiáveis, heterogêneas e nômades. A reversão do plano para o mapa conduziria a uma liberação do modelo arbóreo que domestica o corpo, a mente, a sexualidade, na exata medida que, opondo-se ao decalque, "deve ser produzido, construído, sempre desmontável, conectável, reversível, modificável, com múltiplas entradas e saídas, com suas linhas de fuga" (DELEUZE; GUATTARI, 1995, p. 43).

O que está em jogo na proposta de reversão do planejamento linear e arborescente com suas vias traçadas horizontal e verticalmente em mapa é 
que se trata de um modelo sem centro e sem hierarquias, comprometido com o devir. Se a modelo arbóreo propõe filiações, genealogias e fundamento de todas as coisas, o modelo rizomático dá conta de territórios não marcados e de alianças, rompendo com um sistema que tem como alvo direções de base ontológicas e que passa a "perceber as coisas pelo meio" (DELEUZE; GUATTARI, 1995, p. 46), sem começo ou fim, de forma que o pensamento devenha nômade.

Com base no exposto, percebe-se que se está ainda muito distante da realização de tal ruptura, pois não se trata de um corte mas da desmontagem de um sistema que domina todas as áreas do saber, o pensamento humano e o modo de viver ocidental. Talvez seja uma tarefa hercúlea e idealizante, pois não seria nada fácil romper com a ontologia, com a história, com a transcendência, com a ideia de sujeito, com a ideia de semear tão caras ao Ocidente. Não seria igualmente fácil abrir mão de perguntas que se preocupam com a direção e que norteiam as ações didáticas: "Para onde você vai? De onde você vem? Aonde quer chegar? " (DELEUZE; GUATTARI, 1995, p. 48). Origem, objetivos e finalidades agenciam respostas que são verdadeiros decalques e que reproduzem imagens que visam a sedentarizar a humanidade, o pensamento e o saber. E como seria passar a movimentar-se no meio das coisas, já que o modelo consagrado privilegia o início e o fim, a linearidade, a profundidade e o que pode ser localizado?

Sabendo-se, de antemão, quão complexa tarefa seria instalar o sistema rizomático na elaboração de mapas voltados para o ensino de literatura e de leitura, justamente porque abalaria a compreensão do livro cultural enquanto representação de mundo. Seu lugar seria ocupado pelo livro anticultural, que "faz uso ativo de esquecimento e não de memória, de subdesenvolvimento e não de progresso a ser desenvolvido, de nomadismo e não de sedentarismo, de mapa e não de decalque." (DELEUZE; GUATTARI, 1995, p. 47). Claro que o momento parece bastante oportuno para que se comece a pensar em reversão de modelos, especialmente quando o Estado não representa mais nada, favorecendo o desenraizamento, pois, afinal, no Brasil de todo sempre, as coisas mais importantes sempre aconteceram no meio. Política, social e educacionalmente pensando a condição do povo brasileiro, a 
estrutura rizomática é uma constante seja, por exemplo, no modo de habitar, de ocupar a cidade, de capturar informações, porque é um povo que tem "jogo de cintura“ (DELEUZE; GUATTARI, 1995, p. 48).

Porém, enquanto se estuda a possibilidade de se ter mapas em lugar dos convencionais planejamentos, há um modo de transição bem menos radical e que pode abrir, posteriormente, picadas para a elaboração de mapas. O modo de transição a que se refere diz respeito ao assentamento de campos de leitura ${ }^{6,}$ um modo de planejar que se baseia na estrutura dos móbiles, a fim de dinamizar o ensino de literatura, recorrendo a diferentes linguagens, formas e gêneros regulados ainda em uma ordem binária da qual se gostaria de escapar: convergência e divergência.

A montagem de móbiles não abre mão da variedade, mas ainda não está livre de centramentos -- temas organizadores --, embora possibilite várias aberturas para saídas e entradas. Da perspectiva metodológica, os temas podem ser trabalhados de modo que funcionem "como a dominante semântica e não como uma ideia exclusiva", expondo o aluno-leitor a uma “situação aberta ao confronto e à analise", como sugerem os organizadores -Dirce Riedel, Carlos Lemos, Ivo Barbieri e Terezinha Castro -- de Literatura brasileira em curso, uma antologia de textos que, pelos idos dos anos sessenta, substituiu pela divisão temática o convencional esquema de ordenação de textos literários em obras didáticas, com o propósito de desencadear "um feixe de imagens e associações" (p. 48). Avessa às direções padronizadas, a antologia, que até os anos setenta era adotada no curso de formação de professoras do Instituto de Educação, possui feição de móbile, porque se constitui em um livro "desmontável, podendo ser armado de muitas maneiras a critério de quem lê ou estuda" (p.49).

Foi nesta antologia que se encontrou inspiração para os campos de leitura que situassem o estudante-leitor em um contexto cultural e literário que o fizesse sair da posição confortável e predeterminada que ocupa em

\footnotetext{
${ }^{6}$ Cf. GENS, Armando. $\mathrm{O}$ ensino de literatura brasileira nas Faculdades de Formação de Professores: propostas metodológicas. In: Anais do 13ㅇ COLE. Campinas, SP: Unicamp, 2003. Acesso: http://alb.com.br/arquivomorto/edicoes_anteriores/anais13/arquivos/seminarios/gens_armando.htm
} 
planos imóveis orquestrados pelas leis de causa, finalidade, consequências -como se a literatura se realizasse como evolução---, e ocultamento das linhas de fuga tão mais significativa para o devir da literatura, do livro e da leitura.

Para a confecção de campos de leitura, é imprescindível criar zonas de articulação entre o popular e o culto, entre o midiático e o folclore, entre as obras canônicas e as ditas marginais, entre as obras do passado e as produzidas na contemporaneidade, entre a literatura e as demais modalidades da arte. Deve-se, também, abrir espaços para acolher as diferenças de gosto e de estética, assim como realizar contextualizações calcadas não só nas cenas gráfica e digital mas também na área do design.

A instalação de campos de leitura tem por princípio ativo a dinamização de vários textos. Reúnem-se, para cada campo de leitura, textos de natureza e tempo diversos, que possam dar conta da multiplicidade que um tema pode incorporar. Fica patente que, em um campo de leitura, a intenção de valorizar a diversidade e propor relações ainda não pensadas de forma acadêmica ou escolar ganham destaque. A intenção maior é propor uma espécie de mestiçagem -- naquela fórmula cantada por Jackson do Pandeiro: "chiclete eu misturo com banana" -- que franqueie a estudantes-leitores entrarem em contato com diferentes vozes, questões de gênero, ritmos variados e diferentes textos, de forma a intensificar o caráter híbrido e romper com o pensamento hierarquizado que procura deter o processo de hibridização das culturas, tão bem expressas nas colocações preconceituosas que certos grupos dirigem às manifestações populares que possam ferir o conjunto de valores da academia ou da escola.

Através da convivência com textos variados, estudantes-leitores compreendem a importância da linguagem, de estilos e dos ritmos corporais, intelectuais e emotivos como marcas de diferença no desenvolvimento dos temas. Pintura, fotografia, grafitti, cultura hip-hop participam dos campos de leitura. Analisam-se imagens de mulheres, de homens e de escritores registrados pelo olhar de pintores em contraposição às imagens fotográficas colhidas em jornais e revistas da atualidade e do passado, de modo que os campos de leitura, rompendo com esquema cronológico em flecha, proponham um jogo de temporalidades através da dinamização de diferentes 
materiais. Cabe ao livro, ao jornal, ao tabloide e às revistas ampliarem as divisas do que se conhece por literário; afinal, literatura e leitura não se restringem somente ao espaço-livro. Por isso mesmo, não se pode esquecer de incluir as manifestações da literatura oral, como, por exemplo, poema falado.

A proposta de elaboração de campos de leitura pretende ser uma linha de fuga do esquema de aquisição de conhecimento pautado pela seriação, pela linearidade, pela progressão e, ao mesmo tempo, demonstrar que características de estilos de época, tipologias, habilidades predefinidas, leituras-decalque não garantem a formação do leitor. Muitas vezes acabam por banir a leitura e impedem os estudantes de habitarem no espaço poético. Seria desejável que o ensino de literatura e da leitura literária não mais se realize em linha reta. Por isso, valeria correr o risco de investir na variedade textual e na interdisciplinaridade, de modo que os estudantes vivenciem um estado de leitura literária que se organize, não ainda como rizoma, mas como redes que possam ultrapassar modelos de confinamento, de repressão e de automação, para que se efetivem processos de formação de subjetividade através do ensino de literatura e da leitura literária em uma sociedade desigual, liquefeita e regulada por padrões de consumo.

\section{Referências}

ANDREATO, María Teresa. La lectura, outra revolución. México: Fondo de Cultura Económica, 2014.

BRANCO, Lúcia Castelo. O que é erotismo? 2. ed. São Paulo: Brasiliense, 1987.

CARON, Bettina. Pós-modernidad y lectura: la lectura literaria en la construcción de la subjetividad. 1. ed. Ciudad Autónoma de Buenos Aires: Libros del Zorzal, 2012.

DELEUZE, Gilles; GUATTARI, Félix. Mil platôs. capitalismo e esquizofrenia. Trad. Ana Lúcia Oliveira, Aurélio Guerra Neto e Celia Pinto Costa. São Paulo: Editora.34, 1995. Vol.1(Coleção TRANS)

FOUCAULT, Michel. A grande estrangeira: sobre literatura. Tradução de Fernando Scheibe. Belo Horizonte: Autêntica, 2016. 
LITERATURA E ENSINO: "OUEM SABE LER ENXERGA MELHOR..."

MONTES, Graciela. La frontera indómita: en torno de la construcción del espacio poético. México: Fondo de Cultura Económica, 1999.

PETIT, Michèle. A arte de ler ou como resistir à adversidade. Trad. Arthur Bueno e Camila Boldrini. São Paulo: Editora 34, 2009.

--_--_. Os jovens e a leitura. Trad. Celina Olga de Souza. São Paulo: Editora 34,2008

RIEDEL, Dirce; LEMOS, Carlos; BARBIERI, Ivo; CASTRO, Therezinha. Literatura brasileira em curso. Rio de Janeiro: Edições Bloch, 1968.

SARLO, Beatriz. Tempo presente. notas sobre a mudança de uma cultura. Trad. Luís Carlos Cabral. Rio de Janeiro: José Olympio, 2005.

SHOWALTER, Elaine. Teaching literature. Malden, USA: Blackwell, 2007.

TODOROV, Tzvetan. A literatura em perigo. Tradução de Caio Meira. Rio de Janeiro: DIFEL, 2009.

VAZ, Sérgio. Flores de alvenaria. São Paulo: Global, 2016.

Recebido em 12 de novembro de 2016.

Aceito em 6 de dezembro de 2016. 
